\title{
Relation between Selected Water sources their location and Occurrence of Bacteria in Private House Hold water supply in district Nowshera KPK
}

\author{
Aamir Gul ${ }^{1}$, Prof. Amjad $\mathrm{Ali}^{2}$ \\ ${ }^{I}$ Department of Civil Engineering UET Peshawar KPK Pakistan \\ ${ }^{2}$ Department of Civil Engineering UET Peshawar KPK Pakistan
}

\begin{abstract}
Water is life. This simple statement embodies the central role water plays to individuals, families, communities, nations and regions. The study was carried out for the bacteriological quality assessment of drinking water and identifies the problems related to water quality, impact of the microbiological quality of water from house hold sources (hand pumps) on public health indicators. The scope of work is limited to private water sources and their specific microbiological quality in three union councils of Nowshera including Tarrujabba, AmanKot and Akbar Purra. With a little variance in percentage of Other acute Diarrhea reported from the BHUs in these union councils it is concluded that Bacteriological contamination of the water sources has significant impact on the public health in these union councils, causing huge number of water born morbidities and posing continuous threat to develop in to potential water born disease alerts and outbreaks.
\end{abstract}

Key Words: Bacteria, Diarrhea, Disease, House Hold, Water sources

\section{Introduction}

More than one billion of people do not have an enough and safe drinking water supply off which 800 million are in rural areas. Nearly there are 2.5 million deaths and 4 billion cases due to waterborne diseases together with diarrheal and dysentery diseases have been recorded, to which waterborne pathogens are a major contributor and even more. According to World Health Report 1998, the waterborne disease is widespread in many developing countries, therefore an adequate supply of safe drinking water is one of the leading basics for healthy an energetic life (Nieuwenhuijsen et al, 2000 (i.e .,[1]). But the rising drought of potable water supplies are is among the most important issues which are facing by many cities, and even countries, mostly those using single sources of water. Due to a numbers of problems in the results, the urban centers are looking to other sources of water supplies (Howar et al., 2006 ( i.e .,[2]). Pakistan is among few developing countries where access to safe drinking water falls under satisfactory levels. An independent study reports that no more than $25 \%$ of the population has sustainable access to quality drinking water (Neils, 2005 (i.e .,[3]).

The worldwide population nowadays consumes untreated, non piped drinking water, usually consisting of small volumes $(<40 \mathrm{~L} / \mathrm{d})$ collected and stored in the home by users. Usually, people collect water from any accessible source and store it in a vessel in the home for domestic and potable use, often without treatment and protection from further contamination. In many cases, such collected household water is often heavily contaminated with faecal microbes and poses risks of exposure to waterborne pathogens and thus to infectious diseases (Gasana et al., 2002(i.e .,[4])

Now it is universally known by water and medicinal experts that the greatest risk associated with the intake of water is the microbial risk due to water contamination by human and/or animal feces (WHO, 2004a( i.e .,[5]). It is reported that in 2000 , the need of access to safe water remained a problem for over a billion people worldwide, and inadequate sanitation services affected at least 2.4 billion people (Mintz et al., 2001( i.e .,[6]). Low water quality, sanitation and hygiene account for some 1.7 million deaths a year worldwide, mainly through the communicable diarrhea (Ashbolt, 2004 ( i.e .,[7]). Diarrheal diseases, which are frequently transmitted by contaminated water is a leading cause of morbidity and mortality among children under the age of 5 years in developing countries. Reported that annual total mortality from diarrheal diseases ranges from 2.5 to 3.5 million and more than $80 \%$ are among children under 5 years of age (Kosek et al., 2003( i.e .,[8]). Global morbidity is estimated at 4 billion episodes per year, of which $30 \%$ (1.2 billion episodes per year) are related to polluted water (Ford, 1999( i.e .,[9]).

The main objective of this study is to identify the problems related to water quality in these areas, to study the impact of the quality of water on public health indicator and to suggest the ways and means to tackle solve this problem 


\section{Materials and Methods}

These details are basically about the study area its geographical location, general trend of occupation, Data collection, water sampling and testing.

Laboratory techniques for microbe's

\subsection{Total Plate Count (TPC)}

Total plate count was determined by pour plate method. Serial dilutions (10-1 to 10-4) of the water samples were made and aliquots of $1 \mathrm{ml}$ were added to each duplicate Petri dish. Total Plate Count Agar was added to each Petri dish for total plate count and incubated at $35^{\circ} \mathrm{C}$ for $48 \pm 2$ hours. After incubation colony was counted by colony counter and results were expressed as cfu/ml (APHA 2005).

\subsection{Total Coli-form Bacteria (TCB)}

The Most Probable Number (MPN) of total coliforms bacteria were determined by multiple tube fermentation technique (APHA 2005). $1 \mathrm{ml}$ from the previously prepared 10-1, $10-2$ and $10-3$ dilutions were inoculated into three replicate tubes containing $10 \mathrm{ml}$ of Lauryl Triptose (LT) Broth with inverted Durham tubes and incubated at $35^{\circ} \mathrm{C} \pm 0.5{ }^{\circ} \mathrm{C}$ for 24 and $48 \pm 2$ hours after inoculation. Tubes were examined for evidence of gas production at the end of 24 hours incubation. Gas production was measured by gas displacement in the inverted vial and also effervescence produced, when the tube was gently shaken. Negative tubes were reincubated for additional 24 hour and again examined for gas production. Positive tubes with gas formation and turbidity were sub-cultured into Brilliant Green bile (2\%) (BGB) broth and incubated at $35{ }^{\circ} \mathrm{C}$ for 48 hours. Total coli-form was calculated from MPN tables as per $100 \mathrm{ml}$ (APHA 2005).

\subsection{Total Fecal Coli-form Bacteria (TFC)}

Tubes having $10 \mathrm{ml}$ E.C. broth with inverted Durham tubes was inoculated by means of $3 \mathrm{~mm}$ loop from the presumptive fermentation tubes showing gas and incubated at $44.5^{\circ} \mathrm{C}$ for 24 hours and examined for gas production. Fecal Coliform was calculated from MPN tables (APHA 2005( i.e .,[10]).

\subsection{E. Coli}

Eosin Methylene Blue (EMB) Agar was used for the identification of E. coli. All the tubes of E.C. broth showing gas were subculture by streaking on EMB agar plates and incubated at $35{ }^{\circ} \mathrm{C}$ for $18-24$ hours. Positive plates contained typical colonies with green metallic sheen were inoculated on PCA slants (plate count agar) and incubated at $35{ }^{\circ} \mathrm{C}$ for $18-24$ hours. After 24 hours incubation the typical colonies were confirmed by biochemical tests and also by kits E.ColiO157:H7 latex test reagent kit Pro Lab. Canada (APHA 2005).

\subsection{Test Procedure}

Pipette $01 \mathrm{ml}$ each of test portion and inoculate into $10 \mathrm{ml}$ of Lauryl Tryptose Broth.

Incubate at $35 \pm 0.5^{\circ} \mathrm{C}$ for $48 \pm 3 \mathrm{hr}$. Observe gas production after $24 \mathrm{hr}$ and continue incubation (presumptive identity).

After $48 \pm 3 \mathrm{hr}$ of incubation in Lactose Broth medium agitate the gassing Lauryl tubes, take a loop ful from lactose tubes containing higher concentrations of inocula and transfer to BGB tubes respectively.

Incubate BGB tubes at $35^{\circ} \mathrm{C}$ for $48 \pm 2 \mathrm{hr}$.

Observe gas production for confirmation and record.

\section{Results and Discussions}

The results and discussion chapter has integrated into two main themes and then every theme was sub divided into sub headings in order to address the respective research question in each objective. The two main themes are water quality and health. The results were noted down and then discussed under each sub heading.

\subsection{Results}

\subsubsection{Total Coliform}




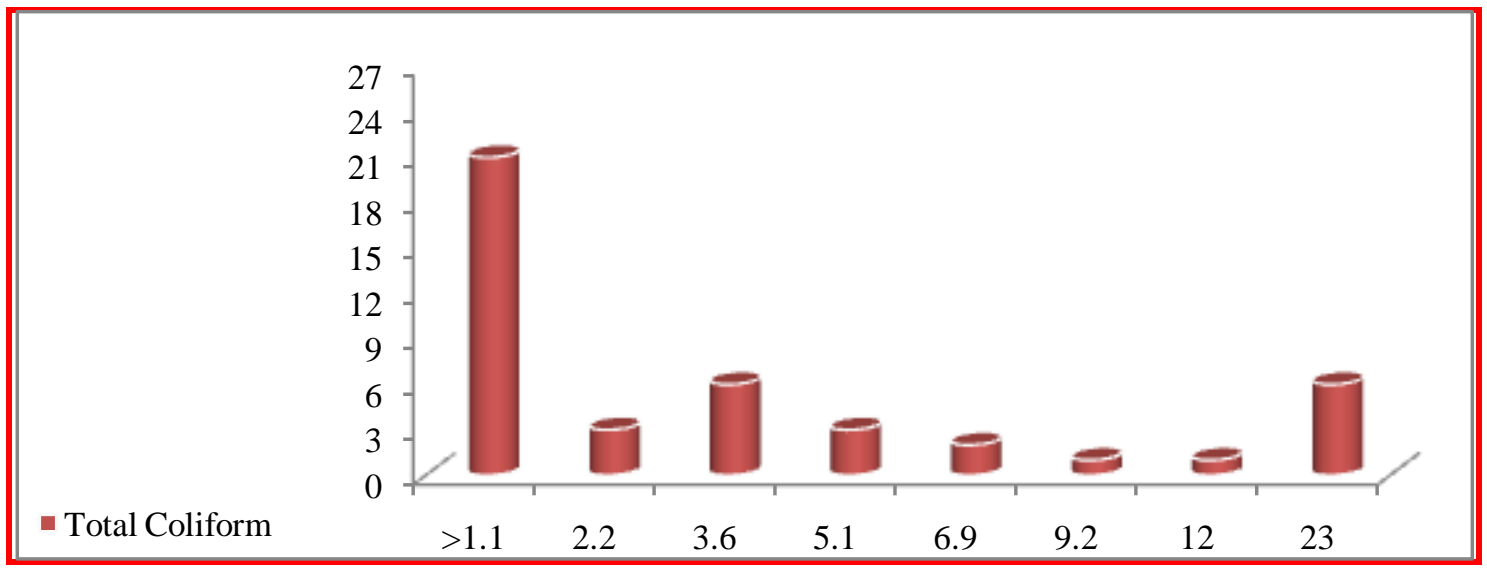

Fig. 1

45 samples were collected from different private water sources (Hand pumps) from different location. All the proper SOPs (as described in water sample collection and transportation for microbiological testing) were followed. After testing water samples for Total plate Count these samples were tested for presence of total coil form bacteria or TCB using the technique mentioned in Laboratory technique for microbes. The Most Probable Number (MPN) of total coliforms bacteria were determined by multiple tube fermentation technique (APHA, 2005). Out of 45 water samples 24 samples werepositive for Total coliform bacteria which means $53 \%$ of the total samples collected were contaminated.

\subsubsection{Fecal Coli form}

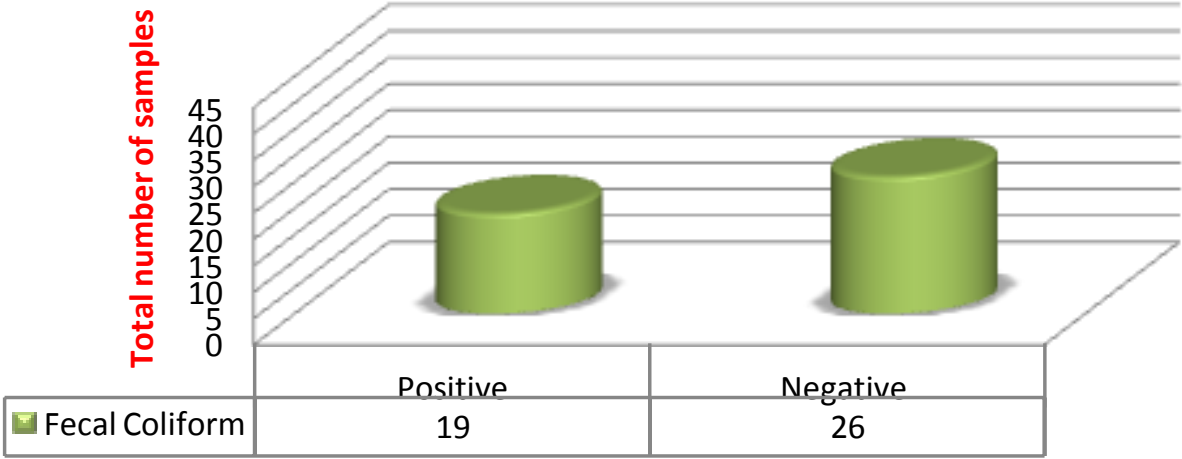

Fecal Coliform

Fig. 2

After confirmation of the sample being contaminated by Total coliform bacteria these samples were further tested for presence of Total Fecal coliform Bacteria or TFC using the technique mentioned in Laboratory techniques for microbes. 19 out of 45 water samples were found faecally contaminated which means $42 \%$ of the total water samples collected were contaminated.

\subsubsection{E-Coli}

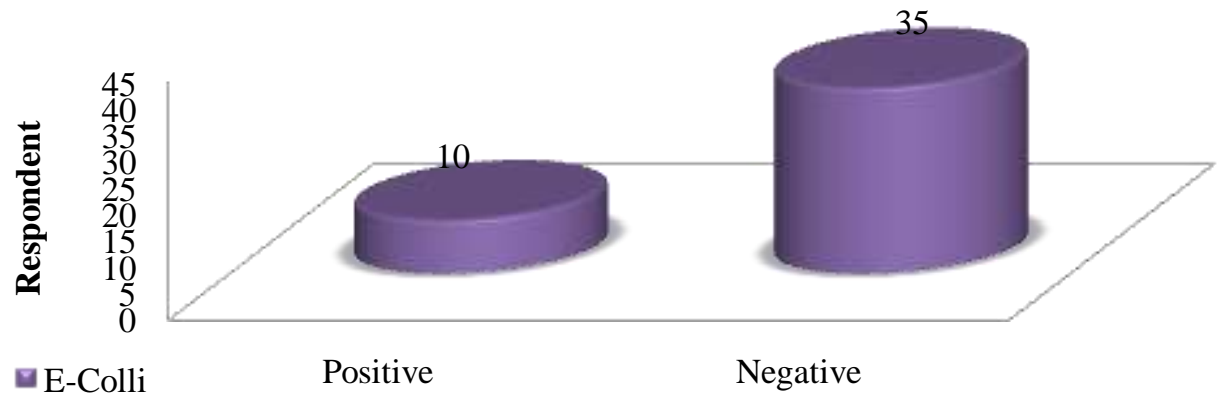

Fig. 3 
The samples were further processed following the technique mentioned for identification of E. Coli. The above graph show that 10 out of 45 water samples which mean $23 \%$ of the samples collected were positive for the identification of E. coli.

\subsection{Discussions}

Disease early warning system DEWS is system implemented by World health organization for early detection and response of any communicable disease alert or outbreak in Pakistan. Disease early warning system contains a list of communicable diseases which can develop into potential alerts or outbreaks resulting into increased morbidities and mortalities. In this discussion one particular disease on top of the list of communicable diseases related to water quality Acute Diarrhea is discussed with its relation to water quality testing conducted.

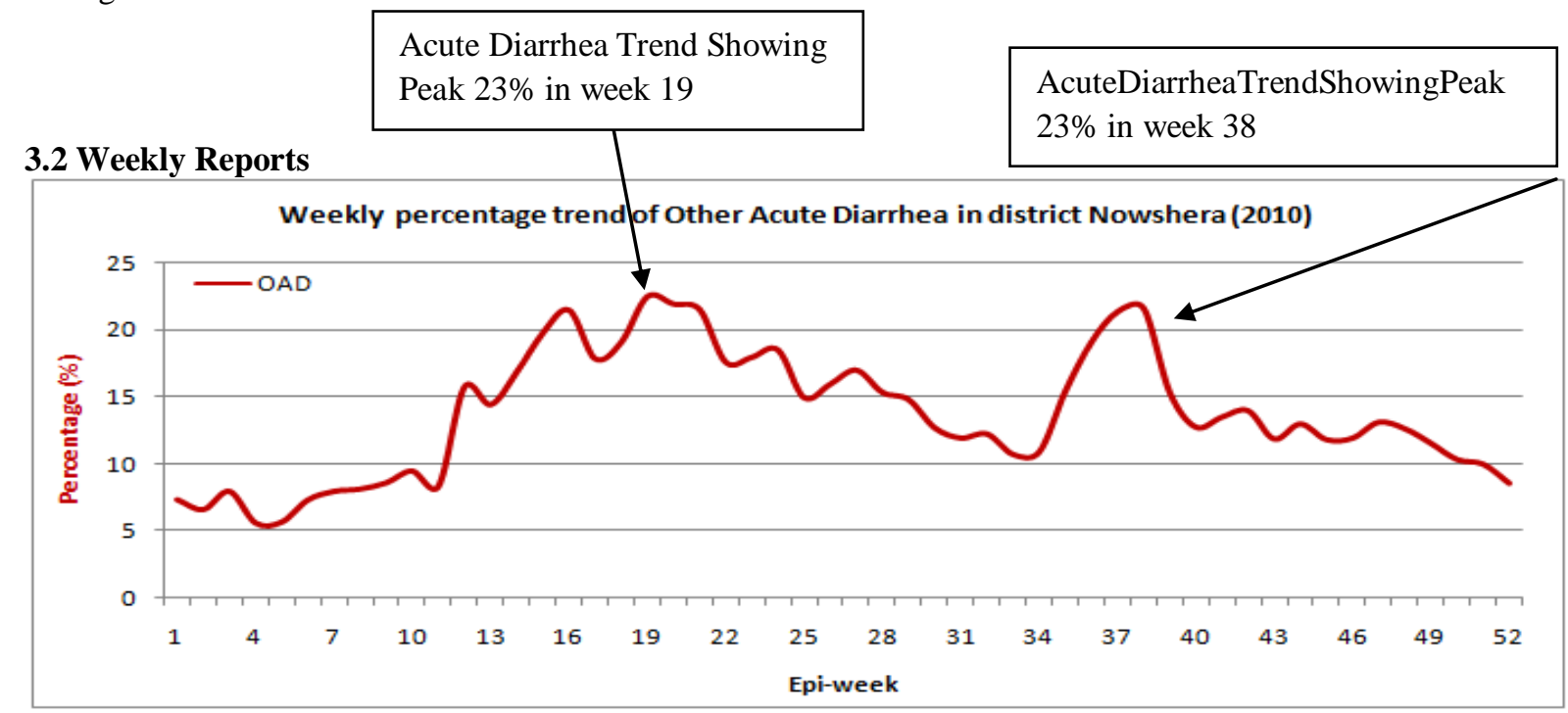

Fig. 4

The above graph shows the Other Acute Diarrhea (OAD) as percentage of cases out of total consultations were reported to DEWS (Disease Early Warning System) from week 1 to 52, 2010 (January to December, 2010). From week 10 to 26 (March to Jun) OAD percentage trend was showing high pick due to involving more health facilities in DEWS. Rapidly decreased of percentage trend in July (from week 30 to 34) due to devastated flood i.e. less health facilities (functional) were reported to DEWS. Situation from week 35 to 40 (August and September) threshold in percentage due to increased OAD patients after flood. From September to December (Week 41 to 52) OAD percentage trend was showing decrease due to intervention and responding of DEWS, EHE team in district Nowshera.

AD Showing peak in Tarru Jaba during week 14 reaching 58\%,Aman kot 51\% during week 18 and Akbar pura $49 \%$ during week 15

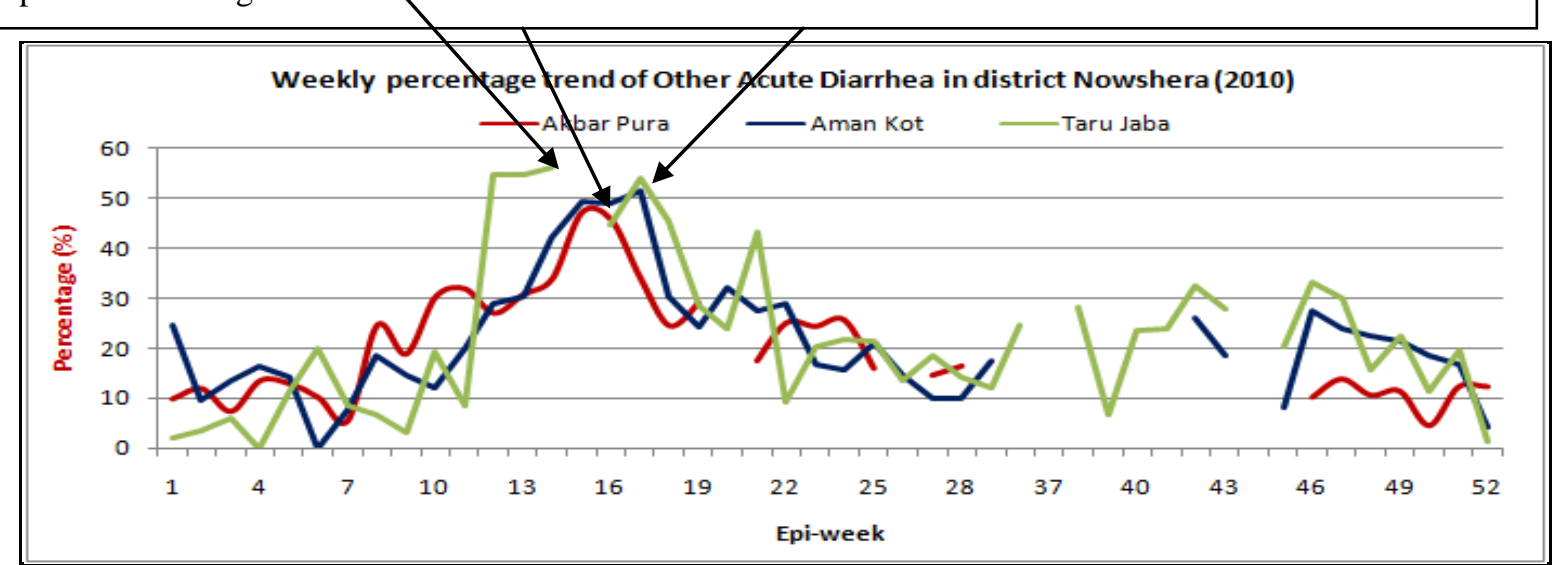

Fig. 5

The above graph shows the Other Acute Diarrhea (OAD) consultations percentage of Akbar Pura, AmanKot and TaruJaba health facilities from week 1 to 52, 2010 (January to December, 2010). The fluctuation and low consultations percentage reporting during week 31 to week 45 is showing due to devastated flood. 
Other acute diarrhea reached $16 \%$ at its peak value during week 38

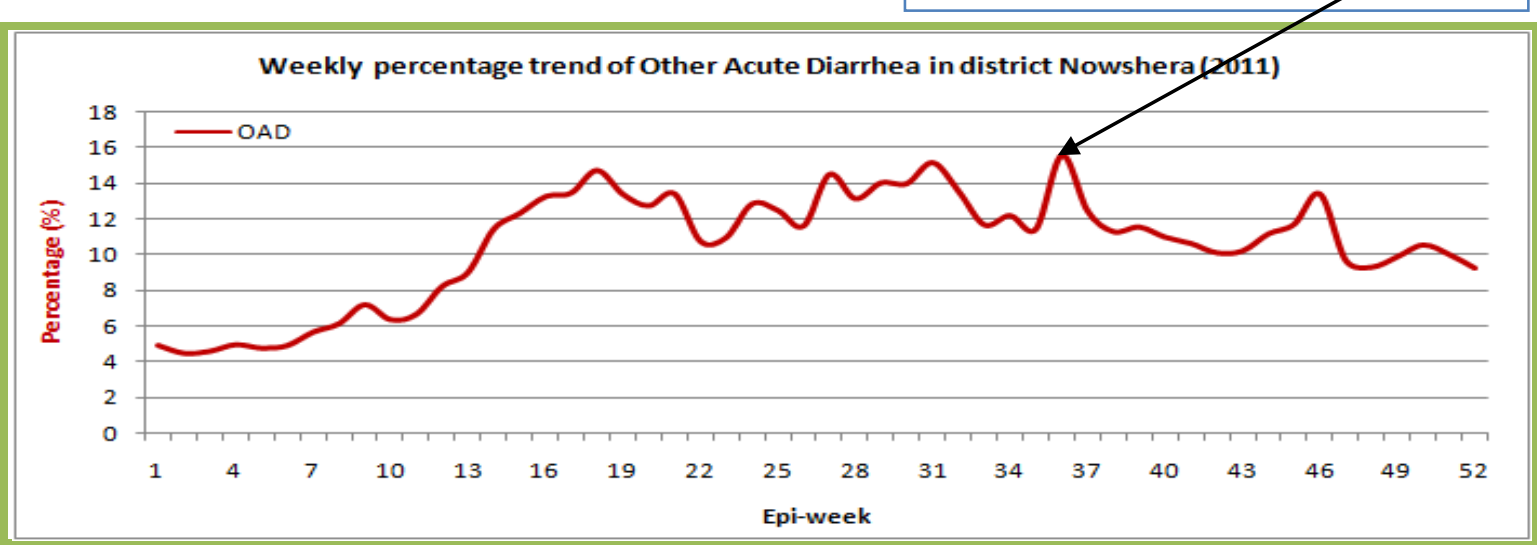

Fig. 6

The above graph shows OAD consultations percentage of district Nowshera from week 1 to 52, 2011. From week 14 to 38 shows fluctuation in percentage trend due to seasonal effect.



Fig. 7

The above graph shows the Other Acute Diarrhea (OAD) consultations percentage of Akbar Pura, Aman Kot and TaruJaba health facilities from week 1 to 52, 2011 (January to December, 2010). The low reporting consultations during week 30 to 40 is showing due to lack of Surveillance Officer in district Nowshera.

\section{Conclusions}

After completing the field study, laboratory work and discussions on related data on two integral themes of the study including water quality and Health parameters following conclusion is with drawn

a. The main water sources in the area under study are hand pumps.

b. The level of Bacteriological contamination (Total coliform 53\% (Fig. 1), Feacal coliform $42 \%$ (Fig. 2) and E. coli $23 \%$ ( Fig. 3)) of the hand pumps as discussed in the results section is very high.

c. During 2010 the peak of the diarrhea trend recorded for District Nowshera was 23\% (Fig.4) (Mean OAD was responsible for $23 \%$ of the total consultation of the health facilities). While peak OAD trend recorded for Tarru Jaba is $58 \%$ (Fig 5). This is 2.52 times or $252 \%$ more than the overall district OAD trend peak.

d. The peak OAD trend for 2010 in Union Council (UC) Aman kot reported from BHU (basic health unit) Aman kot is $51 \%$ (Fig.5) which is 2.21 times or $221 \%$ more than the Peak OAD in District Nowshera.

e. The Peak OAD trend for 2010 in UC Akbar pura reported from BHU Akbar pura is $49 \%$ (Fig 5) which is 2.13 times or $213 \%$ more than the peak OAD trend for the district Nowshera.

f. The Peak OAD trend for 2011 in District Nowshera is 15\% (Fig.6)

g. The Peak OAD trend for 2011 in UC Aman Kot reported from BHU Aman kot is 26\% (Fig. 7) which is 1.73 times or $173 \%$ more than the peak OAD recorded for district Nowshera 
h. The Peak OAD trend for 2011 in UC Akbar Purra reported from BHU Aman kot is 24\% (Fig.7)which is 1.6 times or $160 \%$ more than the peak OAD recorded for district Nowshera

i. The Peak OAD trend for 2011 in UC Aman kot reported from BHU Aman kot is $23 \%$ which is 1.53 times or $153 \%$ more than the peak OAD recorded for district Nowshera

j. With a little variance in percentage of OAD reported from the BHUs in these union councils it is concluded that Bacteriological contamination of the water sources has significant impact on the public health in these union councils, causing huge number of water born morbidities and posing continuous threat to develop in to potential water born alert and outbreak

k. The public health indicators in these areas clearly suggest that bacteriological contamination of water sources is permanent threat to the Public health and this huge number of morbidities can convert to mortalities resulting in human loss if the matter is not addressed properly.

\section{References}

[1] Nieuwenhuijsen MJ, Toledano MB, Eaton NE, Elliott P, Fawell J(2000) Chlorination disinfection by-products in water and their association with ad zerse reproductive outcomes: a review. Occup Environ Med ; 57:73-85.

[2] Howar G ,Schmoll O, Chilton J, and Chorus I (2006). Protecting the ground water for health, managing the quality of drinking water sources. World Health Organization report, Chapter 18, 1-24.

[3] Neils R (2005) Drinking water crisis in Pakistan \& issue of bottled water-Nestle's 'Pure Life' in Pakistan

[4] Gasana J, Morin J, Ndikuyeze, A. and Kamoso P (2002). Impact of Water Supply and Sanitation on Diarrheal Morbidity among Young Children in the Socioeconomic and Cultural Context of Rwanda (Africa) Environmental Research Section A, 90, 76-88.

[5] WHO (2004), Water Sanitation and Hygiene, Facts and Figures, http://www.who.int/water sanitation health/publications /factsfigures04/en/

[6] Mintz E, Bartram J, Lochery P. \&Wegelin, M(2001) Not just a drop in the bucket: expanding access to point-of-use water treatment systems. Am. J. Pub. Hlth 91, 1565-1570

[7] Ashbolt NJ (2004). Microbial Contamination of Drinking Water and Disease Outcomes in Developing Regions. Toxicology, 198, 229238

[8] Kosek M, Bern C, Guerrant RL (2003). The global burden of diarrheal disease, as estimated from studies published between 1992 and 2000. Bull. W.H.O. 81, 197-204

[9] Ford TE (1999). Microbiological Safety of Drinking Water: United States and Global Perspectives. Environmental Health Perspectives 107, 191-206. [This is a review of data on global waterborne disease incidence].

[10] APHA(2005).Standards Methods for the Examination of Water and Wastewater, 21st edition, American Public Health Association, Washington, D.C. 